\title{
Characterisation of the dilatational stress relaxation for viscoelastic Polyurethane materials
}

\author{
A. Consil ${ }^{1, a}, N$. Billon $^{2}$ and L. Laiarinandrasana ${ }^{1}$ \\ ${ }^{1}$ MINES ParisTech - MAT Centre des Matériaux, CNRS UMR 7633, BP 87, 91003 Evry Cedex, \\ France \\ ${ }^{2}$ MINES ParisTech - CEMEF CNRS UMR 7635, 06904 Sophia Antipolis, France
}

This contribution deals with three grades of polyurethane (PU) devoted to ensure sealing of filter cartridge endplate. PU is an amorphous polymer whose microstructure depends on the supplier processing. During service, the endplates are submitted to complex thermo-mechanical loading consisting of an applied pressure with a continuous increase of the temperature. The inner diametrical dilatation is the key parameter that has to be controlled. The main loading deals then with transient thermal expansion as well as hydrostatic pressure.

Experimental results on Dynamic Mechanical Analysis (DMA) and uniaxial compression tests were carried out allowing comparing the evolutions of the Young's modulus with temperature for both kinds of tests [1]. Assuming linear elasticity, the stress state in the endplate could be calculated via Hooke's law. The glass transition temperature Tg is included in the working temperature range [$\left.40^{\circ} \mathrm{C} ; 160^{\circ} \mathrm{C}\right]$. Therefore, the materials evidenced viscoelastic deformation. Particularly, the characterization of viscoelastic deformation under a dilatational part of the stress tensor is needed.

The microstructures of the three PU's were examined by using Scanning Electron Microscope (SEM). Initial porosity was evidenced, which presumably has influence on the materials' response on hydrostatic pressure. Two specific experimental procedures were performed:

- The first one deals with digital image correlation of painted speckles allowing the measurement of the full-field displacement. This enables to determine the Poisson's ratio;

- The second consists of stress relaxation measurement under confined compression. The stress state is merely hydrostatic.

Viscoelastic constitutive equations were implemented in an in house finite element (FE) code [2]. A set of materials' coefficients was identified by means of an inverse method of the optimizer routine [3]. Thanks to these coefficients, simulation of the engineering component under realistic loading conditions was successfully performed.

\section{References}

1. A. Consil, N. Billon, L. Laiarinandrasana, J.Y. Picard, Proceedings of $14^{\text {th }}$ International Conference on Deformation, Yield and Fracture of Polymers, Rolduc Abbey, Kerkrade, the Netherlands, April 5-9, 2009.

\footnotetext{
a e-mail : angelique.consil@mines-paristech.fr
} 
2. J. Besson, R. Foerch, Computer Methods in Applied Mechanics and Engineering, 142, 145-187 (1997)

3. Besson, J.; Leriche, R.; Foerch, R.; Cailletaud, G., In European Journal of Finite Elements (Revue Européenne des Elémets Finis), P. Breitkopf ed.; Hermes Publ.; Vol. 7(5), p 567-588 (1998) 